\title{
GROUP DECISION SUPPORT SYSTEM (GDSS) UNTUK MENENTUKAN PRIORITAS PROYEK
}

\author{
Nur Heri Cahyana", ${ }^{1)}$ Agus Sasmito Aribowo ${ }^{2)}$ \\ 1,2) Jurusan Teknik Informatika UPN "Veteran" Yogyakarta \\ JI. Babarsari 2 Tambakbayan 55281 Telp (0274) 485323 \\ email : dsnurgeri@gmail.com
}

\begin{abstract}
Every year Yogja Infoservice Company get many offers information technology projects Priority projects need to be done for efficiency and effectiveness of work with the joint meeting mechanism by a number of employees in charge of three things: technical, financial and administrative Each field considered priority projects according to criteria that belong to each of these fields, which of profitable projects to take precedence in a more objective and prioritized by each business unit in the company. Because of the decision reached by the collaborative work of three units of Decision Support Systems must be built Group Decision Support System ( GDSS ). Methods of decision-making for each group using the Weighted Product (WP) and the decisions of each group collaborated with BORDA method. The research methodology uses a System Development Life Cycle and systems development approach using structured methods. Results of the study was a model project selection decision support applications that implement both methods. The results have been tested and can be used in the system .
\end{abstract}

\section{Keyword : Group Decision Support System, BORDA, Priority projects}

Setiap tahun PT. Jogja Infoservice mendapatkan banyak penawaran proyek bidang teknologi informasi. Prioritas proyek perlu dilakukan untuk efisiensi dan efektifitas kerja dengan mekanisme rapat oleh sejumlah pegawai yang membidangi tiga hal yaitu bidang teknis, keuangan dan administrasi. Setiap bidang mempertimbangkan prioritas proyek sesuai kriteria milik masing-masing bidang tersebut, proyek manakah yang menguntungkan untuk didahulukan dan diprioritaskan secara lebih obyektif oleh setiap unit kerja di perusahaan tersebut. Karena keputusan dicapai dengan kolaborasi tiga unit kerja maka Sistem Pendukung Keputusan yang dibangun harus berupa Group Decision Support System (GDSS). Metode pengambilan keputusan untuk setiap group menggunakan Weighted Product (WP) dan hasil keputusan dari setiap group dikolaborasikan dengan metode BORDA. Metodologi penelitian menggunakan System Development Life Cycle dan pendekatan pengembangan sistem menggunakan metode terstruktur. Hasil penelitian adalah model aplikasi pendukung keputusan pemilihan proyek yang menerapkan kedua metode tersebut. Hasil penelitian telah diuji dan dapat dipakai dalam sistem.

Kata kunci : Group Decision Support System, BORDA, Prioritas Proyek

\section{PENDAHULUAN}

Proyek pemerintah maupun swasta dikerjakan dengan sistem tender, dimana proyekproyek tersebut ditawarkan ke perusahaan swasta yang ahli di bidangnya. Pemilihan prioritas proyek merupakan sesuatu hal yang penting karena semakin baik dalam memilih proyek-proyek yang hendak dikerjakan maka keuntungan perusahaan akan maksimal dengan biaya operasional yang minimal. Pemilihan prioritas proyek yang baik juga akan memuaskan semua unit kerja di perusahaan pemegang tender karena terakomidasi kebutuhannya dengan keuntungan maksimal. Setiap tahun Perusahaan Jogja Infoservice mendapatkan penawaran proyek-proyek bidang TIK. Proses pemilihan proyek dilakukan dengan mekanisme rapat oleh sejumlah pegawai yang membidangi tiga hal antara lain bidang teknis, bidang keuangan, dan bidang administrasi. Setiap bidang berhak dan harus turut mempertimbangkan prioritas proyek sesuai kapabilitas masing-masing bidang tersebut, proyek manakah yang menguntungkan untuk didahulukan atau diprioritaskan untuk diraih. Bidang teknis akan memprioritaskan proyek berdasarkan pengalaman kemampuan teknis untuk lingkup pekerjaan yang akan ditawarkan, ketersediaan tenaga ahli, ketersediaan sumberdaya, jadwal pelaksanaan pekerjaan, dan tingkat 
kesulitan pekerjaan. Bidang administrasi akan mempertimbangkan masalah kemudahan proses administrasi pekerjaan, proses transportasi dan akomodasi tim penggarap, proses perijinan jika diperlukan dan proses administrasi lainnya. Sedangkan bidang keuangan akan mempertimbangkan dari penawaran nilai proyek, sisi pengeluaran keuangan untuk tenaga ahli dan penggarap, sisi pengeluaran untuk biaya operasional dan lain-lain. Proses pemilihan proyek yang dilakukan dengan mekanisme rapat bersama membutuhkan waktu pertemuan yang melibatkan banyak personil dan cenderung tidak efisien. Diperlukan sistem pendukung keputusan (SPK) yang dapat membantu menentukan prioritas proyek yang akan dikerjakan. Keputusan dicapai dengan kolaborasi tiga unit kerja tersebut. Dikarenakan ada tiga unit yang harus memberikan dukungan keputusan maka SPK yang dibangun harus mendukung mekanisme Group Decisioan Support System, atau sistem pendukung keputusan beberapa kelompok. Model pengambilan keputusan yang lazim dilakukan untuk alternatif dengan beberapa kriteria adalah metode Weighted Product. Metode ini dapat dipakai untuk menghasilkan rangking sejumlah alternatif dengan mempertimbangkan bobot kriteria setiap alternatif tersebut. Setiap unit kerja di Jogja Info Service akan melakukan perangkingan proyek menggunakan metode Weighted Product ini. Kemudian hasil dari metode Weighted Product setiap unit kerja dikolaborasikan menggunakan metode BORDA. Hasil final merupakan kolaborasi keputusan tiga buah kelompok tersebut sehingga mempermudah pimpinan perusahaan untuk memutuskan proyek-proyek yang akan diprioritaskan.

\section{TINJAUAN PUSTAKA}

\subsection{Penelitian Terdahulu}

Beberapa penelitian tentang group decision support system (GDSS) antara lain oleh Istudor dan Duta (2010) yang meneliti tentang penerapan GDSS untuk bidang ilmu ekonomi. Penelitiannya menjelaskan tentang penggunaan software GDSS bernama Vanguard System untuk aplikasi ekonomi yang mengevaluasi resiko finansial. Penelitian lain tentang GDSS dilakukan oleh Jian Ma yang meneliti tentang penggunaan GDSS untuk memeriksa proyek tugas akhir mahasiswa bimbingannya menggunakan sarana teknologi informasi. GDSS dibangun untuk menyediakan dukungan sistem komputer untuk pengujian secara berkelompok bagi proyek-proyek tugas akhir tersebut

Penelitian sejenis juga pernah dilakukan oleh Putra (2012) dimana GDSS dipakai untuk menentukan lokasi bank dan pimpinan yang tepat untuk bank tersebut. Metode Analytical Hierarkhi Process (AHP) dipakai dalam penelitian tersebut untuk menggabungkan penilaianpenilaian dan nilai-nilai pribadi ke dalam suatu kerangka berpikir yang logis, sehingga memungkinkan keputusan dapat diambil secara efektif. Dalam penentuan lokasi bank dalam penelitian ini dilakukan oleh banyak manager sehingga memerlukan group decision support system. Dalam hal ini digunakan Metode Borda untuk memudahkan mendapatkan keputusan final dari sejumlah keputusan yang dihasilkan oleh manager-manager tersebut

\subsection{Landasan Teori}

\subsubsection{Decision Support System}

Sistem Pendukung Keputusan (SPK) / Decision Support Sistem (DSS) pertama kali diungkapkan pada awal 1970-an oleh Scott Morton yang mengartikulasikan konsep penting sistem pendukung keputusan. Konsep sistem pendukung keputusan ditandai dengan sistem interaktif berbasis komputer yang membantu pengambilan keputusan dengan memanfaatkan data modul untuk menyeleksi masalah-masalah yang tidak terstruktur. (Turban,2005)

\subsubsection{Konsep Group Decision Support System (GDSS)}

System penunjang keputusan kelompok atau group decision support system (GDSS) ialah kombinasi dari Komputer, komunikasi, dan teknologi keputusan dan yang digunakan untuk menemukan, merumuskan, dan memecahkan masalah dalam pertemuan kelompok. Tujuan GDSS adalah untuk pertukaran ide, opini, dan preferensi dalam kelompok.

\subsubsection{GDSS Model BORDA}

Metode Borda ditemukan oleh Jean-Charles de Borda pada abad ke 18. Metode ini digunakan untuk menganalisis keberagaman variabel yang diteliti. Keistimewaan metode ini dapat mengatasi kesulitan pada metode lain dimana orang-orang/ sesuatu yang tidak berada pada rangking pertama akan secara otomatis dihapuskan.

Metode ini sudah secara luas digunakan oleh tim olahraga seperti pool sepakbola, maupun pada seleksi penerima penghargaan musik atau televisi, dll. Contoh perhitungan metode Borda untuk kasus perangkingan proyek adalah sebagai berikut : 
a) Dari hasil kuisioner penilaian proyek dihitung jumlah responden yang menyatakan ranking untuk tiap proyek. Misalnya terdapat 4 responden yang menyatakan proyek A berada di peringkat 2 dan 3 responden menyatakan proyek $A$ berada di peringkat 3 , maka tuliskan angka 4 pada kolom proyek A peringkat 2 dan angka 3 pada kolom proyek A peringkat 3 . $\mathrm{Hal}$ yang sama dilakukan untuk jenis yang lain.

b) Kalikan angka pada kolom peringkat dengan bobot di bawahnya, kemudian tambahkan dengan hasil perkalian pada proyek yang sama, kemudian isikan hasilnya pada kolom ranking. Misalnya untuk proyek $A,(0 \times 2)+(4 \times 1)+(3 \times 0)=4$.

c) Jumlahkan hasil ranking, yang dalam contoh ini berarti: $4+11+5=20$.

d) Untuk mencari bobot tiap proyek, bagi ranking dengan jumlah ranking. Proyek $A=4 / 20=$ 0.2 , dan seterusnya.

e) Proyek dengan bobot tertinggi merupakan yang terpilih untuk mendapatkan prioritas utama.

Tabel 1. Perhitungan Metode Borda.

\begin{tabular}{|c|c|c|c|c|c|c|}
\hline \multirow[t]{2}{*}{ Proyek } & \multicolumn{3}{|c|}{ Peringkat } & \multirow{2}{*}{$\begin{array}{l}\text { Score } \\
\text { Akhir }\end{array}$} & \multirow{2}{*}{$\begin{array}{c}\text { Bobot Setelah } \\
\text { Normalisasi }\end{array}$} & \multirow[t]{2}{*}{ Rangking } \\
\hline & 1 & 2 & 3 & & & \\
\hline $\mathbf{A}$ & 0 & 4 & 3 & 4 & 0.2 & 3 \\
\hline B & 5 & 1 & 1 & 11 & 0.55 & 1 \\
\hline C & 1 & 3 & 3 & 5 & 0.25 & 2 \\
\hline Bobot Peringkat & 2 & 1 & 0 & & & \\
\hline
\end{tabular}

\section{Kontribusi Penelitian}

Bagi PT. Jogja Info Services sistem ini akan membantu proses penentuan prioritas proyek yang akan dikerjakan sehingga perusahaan dapat bekerja dengan efektif dan efisien. Bagi dunia ilmu pengetahuan hasil penelitian ini diharapkan dapat memberikan sumbangan bagi pengembangan ilmu di bidang teknik informatika khususnya sistem pendukung keputusan kelompok.

\section{Metode Penelitian}

Metodologi yang akan digunakan pada penelitian ini antara lain : Studi Pustaka dan SDLC (System Development Life Cycle) yang meliputi tahap Analysis, Design, Implementation, Testing dan Maintenance, (Pressman, 2002).

1. Studi Pustaka

Tahap ini merupakan tahap pengumpulan informasi dan literatur yang diperlukan untuk pembuatan sistem. Adapun informasi dan literatur yang digunakan diantaranya tentang manajemen proyek dan metode-metode Weighting Product dan Borda.

2. Analisis dan perancangan

Pada tahap ini dilakukan analisis serta desain yang diperlukan dalam membuat sistem, diantaranya analisis kebutuhan sistem, analisis proses sistem pendukung keputusan, representasi pengetahuan, mekanisme perangkingan, perancangan DFD, perancangan basisdata dan perancangan user interface.

3. Implementasi

Pada tahap ini, rancangan sistem yang telah dibuat akan diimplementasikan menggunakan pemrograman PHP, Javascript dan MySQL serta program pendukung.

4. Uji coba dan evaluasi

Pada tahap ini, akan dilakukan uji coba dan evaluasi terhadap sistem serta akan dilakukan perbaikan-perbaikan yang diperlukan.

\section{Mekanisme Proses Perangkingan dengan GDSS}

Proses sistem pendukung keputusan untuk perangkingan proyek dengan metode Weighted Product dan Borda mengunakan rumus-rumus atau metode Weighted Product dan BORDA yang sudah lazim dipakai sehingga untuk Weighted Product tidak dibahas secara mendetil. Untuk memberikan penjelasan tentang metode BORDA disajikan dalam contoh kasus di bawah ini.

Misal terdapat 7 buah proyek yang akan dirangking yaitu sebagaimana pada tabel 2 . 
Tabel 2. Contoh Daftar Penawaran Proyek

\begin{tabular}{|l|c|l|l|l|}
\hline No. & ID & \multicolumn{1}{|c|}{ Nama Proyek } & \multicolumn{1}{c|}{$\begin{array}{c}\text { Tanggal } \\
\text { Proyek }\end{array}$} \\
\hline 1 & 1201 & $\begin{array}{l}\text { SIPPK Kementerian } \\
\text { Kesehatan RI }\end{array}$ & $\begin{array}{l}\text { Kementerian Kesehatan RI JI. HR } \\
\text { Rasuna Said Jakart }\end{array}$ & $2012-10-01$ \\
\hline 2 & 1202 & $\begin{array}{l}\text { SMS Gateway PPK } \\
\text { Kemenkes RI }\end{array}$ & $\begin{array}{l}\text { Kementerian Kesehatan RI JI HR } \\
\text { Rasuna Said Jakart }\end{array}$ & $2012-10-01$ \\
\hline 3 & 1203 & $\begin{array}{l}\text { Sistem Data } \\
\text { Center/Warehouse }\end{array}$ & $\begin{array}{l}\text { Kementerian Perikanan dan } \\
\text { kelautan RI }\end{array}$ & $2012-11-01$ \\
\hline 4 & 1204 & $\begin{array}{l}\text { Sistem Informasi Akademik } \\
\text { STIE }\end{array}$ & STIE BPD Semarang & $2012-12-30$ \\
\hline 5 & 1205 & $\begin{array}{l}\text { Network Monitoring } \\
\text { System }\end{array}$ & $\begin{array}{l}\text { Pusat Pengolahan Data di } \\
\text { Kementerian Pekerjaan Umu }\end{array}$ & $2012-10-20$ \\
\hline
\end{tabular}

Sedangkan bobot setiap bagian ditetapkan sebagaimana pada tabel 3 .

Tabel 3. Bobot Bagian di Perusahaan

\begin{tabular}{|l|l|l|}
\hline No & Bagian & Bobot \\
\hline 1 & Teknis & 7 \\
\hline 2 & Administrasi & 4 \\
\hline 3 & Keuangan & 2 \\
\hline
\end{tabular}

Bobot bagian diisi dengan angka kepentingan dalam rang 1 sampai 9 dimana angka tersebut mencerminkan tingkat kepentingan dari bagian tersebut. Semakin tinggi angka maka tingkat kepentingannya juga semakin besar.

Kemudian proses perangkingan internal untuk bagian teknis dilakukan menggunakan 5 buah kriteria sebagaimana pada tabel 4 .

Tabel 4. Kriteria Perangkingan untuk Bagian Teknis

\begin{tabular}{|c|l|c|c|}
\hline No. & \multicolumn{1}{|c|}{ Nama Kriteria } & Bobot & Tipe \\
\hline 1 & Kemampuan Teknis & 5 & Benefit \\
\hline 2 & Ketersediaan SDM & 5 & Benefit \\
\hline 3 & Sumberdaya Pendukung & 4 & Benefit \\
\hline 4 & Kelayakan Penjadwalan & 5 & Benefit \\
\hline 5 & Tingkat Kesulitan & 5 & Cenefit \\
\hline
\end{tabular}

Setelah dilakukan proses perangkingan menggunakan metode Weighted Product diperoleh hasil perangkingan internal bagian teknis sebagaimana pada tabel 5 .

Tabel 5. Hasil Perangkingan untuk Bagian Teknis :

\begin{tabular}{|l|c|l|l|}
\hline No. & ID & \multicolumn{1}{|c|}{ Nama Proyek } & Rangking \\
\hline 1 & 1201 & SIPPK Kementerian Kesehatan RI & 1 \\
\hline 2 & 1202 & SMS Gateway PPK Kemenkes RI & 3 \\
\hline 3 & 1203 & Sistem Data Center/Warehouse & 5 \\
\hline 4 & 1204 & Sistem Informasi Akademik STIE & 4 \\
\hline 5 & 1205 & Network Monitoring System & 2 \\
\hline
\end{tabular}

Kemudian proses perangkingan internal untuk bagian Bagian Administrasi dan keuangan berikut hasil perangkingannya ada pada tabel 6 hingga 9 .

Tabel 6. Kriteria Perangkingan untuk Bagian Administrasi

\begin{tabular}{|c|c|c|c|}
\hline No. & Nama Kriteria & Bobot & Tipe \\
\hline 1 & Administrasi & 3 & Cost \\
\hline 2 & Transportasi & 3 & Cost \\
\hline 3 & Akomodasi & 3 & Cost \\
\hline 4 & Perijinan & 5 & Cost \\
\hline
\end{tabular}


Tabel 7. Hasil Perangkingan dengan WP untuk Bagian Administrasi :

\begin{tabular}{|c|c|c|c|}
\hline No. & ID & Nama Proyek & Rangking \\
\hline 1 & 1201 & SIPPK Kementerian Kesehatan RI & 1 \\
\hline 2 & 1202 & SMS Gateway PPK Kemenkes RI & 2 \\
\hline 3 & 1203 & Sistem Data Center/Warehouse & 4 \\
\hline 4 & 1204 & Sistem Informasi Akademik STIE & 5 \\
\hline 5 & 1205 & Network Monitoring System & 3 \\
\hline
\end{tabular}

Tabel 8. Kriteria Perangkingan untuk Bagian Keuangan

\begin{tabular}{|c|c|c|c|}
\hline No. & Nama Kriteria & Bobot & Tipe \\
\hline 1 & NilaiProyek & 5 & B \\
\hline 2 & FeeSDM & 4 & C \\
\hline 3 & BiayaOperasional & 4 & C \\
\hline
\end{tabular}

Tabel 9. Hasil Perangkingan dengan WP untuk Bagian Keuangan :

\begin{tabular}{|c|c|c|c|}
\hline No. & ID & Nama Proyek & Rangking \\
\hline 1 & 1201 & SIPPK Kementerian Kesehatan RI & 2 \\
\hline 2 & 1202 & SMS Gateway PPK Kemenkes RI & 5 \\
\hline 3 & 1203 & Sistem Data Center/Warehouse & 3 \\
\hline 4 & 1204 & Sistem Informasi Akademik STIE & 1 \\
\hline 5 & 1205 & Network Monitoring System & 4 \\
\hline
\end{tabular}

Setelah hasil perangkingan pada setiap bidang telah dihitung kemudian dikolaborasikan menggunakan metode BORDA sebagaimana pada tabel 10.

Tabel 10. Perangkingan Menggunakan BORDA

\begin{tabular}{|l|l|l|r|r|r|r|r|r|r|r|}
\hline No & \multirow{2}{*}{$\begin{array}{l}\text { ID } \\
\text { Proyek }\end{array}$} & \multicolumn{1}{|c|}{ Nama Proyek } & \multicolumn{3}{|c|}{ Rangking } & Perhitungan & Score & Rangking \\
\hline 1 & 1201 & $\begin{array}{l}\text { SIPPK Kementerian } \\
\text { Kesehatan RI }\end{array}$ & $\mathbf{9}$ & $\mathbf{4}$ & & & & $\mathbf{4 5 + 1 6}$ & $\mathbf{6 1}$ & $\mathbf{1}$ \\
\hline 2 & 1202 & $\begin{array}{l}\text { SMS Gateway PPK } \\
\text { Kemenkes RI }\end{array}$ & & $\mathbf{2}$ & $\mathbf{7}$ & & $\mathbf{4}$ & $\mathbf{8 + 2 1 + 4}$ & $\mathbf{3 3}$ & $\mathbf{3}$ \\
\hline 3 & 1203 & $\begin{array}{l}\text { Sistem Data } \\
\text { Center/Warehouse }\end{array}$ & & & $\mathbf{4}$ & & $\mathbf{9}$ & $\mathbf{1 2 + 9}$ & $\mathbf{2 1}$ & $\mathbf{4}$ \\
\hline 4 & 1204 & $\begin{array}{l}\text { Sistem Informasi } \\
\text { Akademik STIE }\end{array}$ & $\mathbf{4}$ & & $\mathbf{2}$ & $\mathbf{7}$ & & $\mathbf{2 0 + 6 + 1 4}$ & $\mathbf{4 0}$ & $\mathbf{2}$ \\
\hline 5 & 1205 & $\begin{array}{l}\text { Network Monitoring } \\
\text { System }\end{array}$ & & $\mathbf{7}$ & & $\mathbf{6}$ & & $\mathbf{2 8 + 1 2}$ & $\mathbf{4 0}$ & $\mathbf{2}$ \\
\hline Bobot & & & $\mathbf{5}$ & $\mathbf{4}$ & $\mathbf{3}$ & $\mathbf{2}$ & $\mathbf{1}$ & & & \\
\hline
\end{tabular}

Dapat disimpulkan bahwa prioritas proyek ada pada proyek nomor 1 .

\section{Hasil Penelitian}

Implementasi hasil rancangan dalam penelitian ini menggunakan pemrograman berbasis web. Sistem diterapkan secara internal dalam intranet perusahaan. Gambar 1 merupakan halaman utama sistem. Halaman ini memuat sarana login akses sesuai bidangnya. Gambar 2 merupakan halaman hasil perangkingan menggunakan BORDA. Halaman ini hanya dapat diakses oleh pimpiinan dan menjadi salah satu dukungan dalam pengambilan keputusan. 


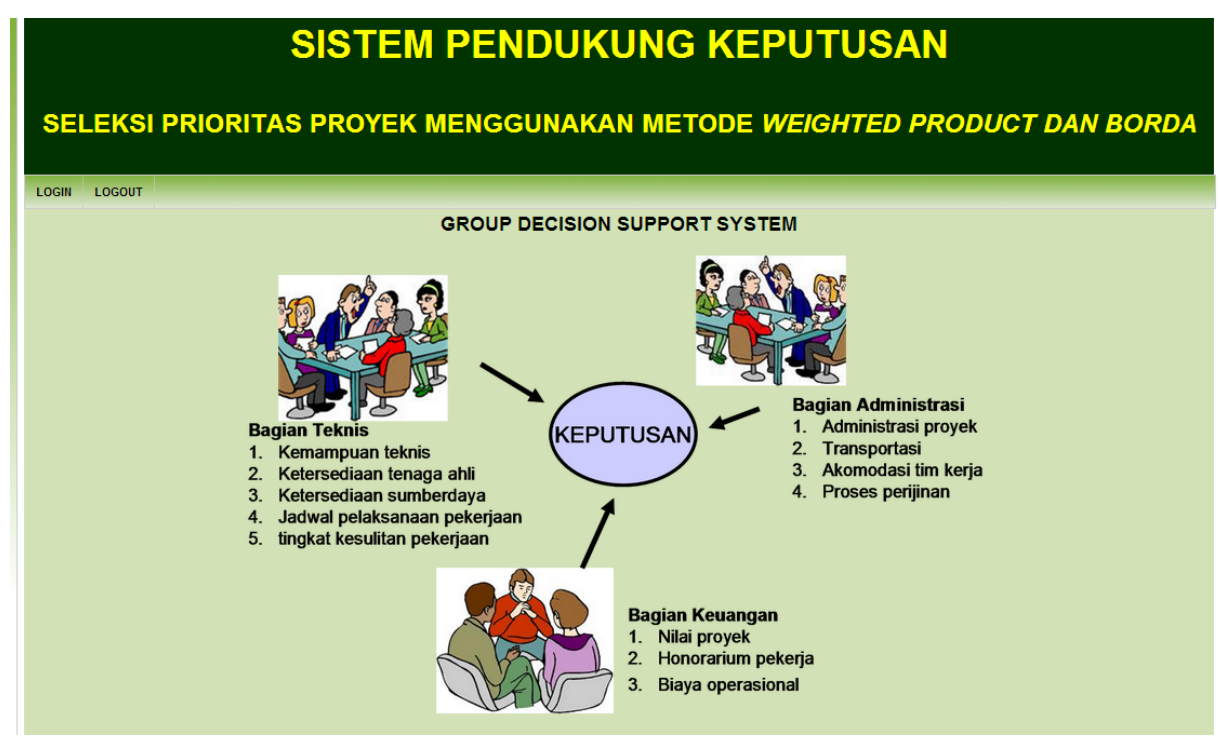

Gambar 1. Halaman Utama Sistem Pendukung Keputusan

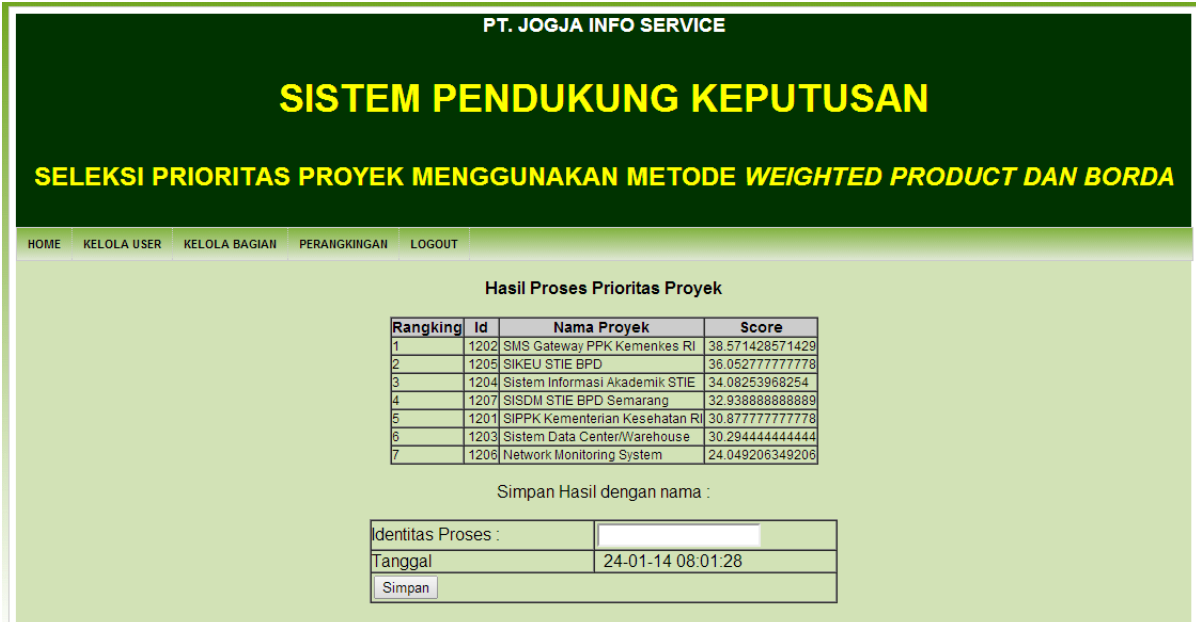

Gambar 2. Hasil Proses WP dan BORDA

\section{Kesimpulan dan Saran}

Proses Weighted Product dan BORDA dapat disinergikan dalam GDSS dan hasil perangkingan dapat membantu pemberian dukungan dalam pengambilan keputusan kelompok. Sebagai saran dalam penelitian adalah diperlukan perbaikan dalam penentuan bobot kriteria dan bobot bagian dalam perusahaan.

\section{Daftar Pustaka}

Istudor dan Duta, 2010, Web-Based Group Decision Support System: an Economic Application, Jurnal Informatica Economică vol. 14, no. 1/2010, Valahia University, Targoviste, Romania

Merijn,Lambert,2000, "Variants of The Borda Count Method for Combining Ranked Clasifier Hypotheses",Proceedings of the Seventh International Workshop on Frontlers in Handwriting Recognition, Amsterdam. ISBN 90-76942-01-3, Nijemegen: International Unipen Foundation, pp 443-452.

Putra, DMDU, 2012, Group Decision Support System Dengan Menggunakan Metode Analytical Hierarchy Process (Ahp) Dan Borda Dalam Penentuan Lokasi Bank Dan Pimpinan Cabang Yang Tepat, Proceeding Seminar Nasional Teknologi Informasi \& Aplikasinya, Ilkom, FMIPA, Udayana

Turban, Efraim, 1995, Decision Support System and Expert System, $4^{\text {th }}$ ed., Prentice-Hall, Inc., New Jersey, pp 472-679 